Rev. Elet. em Gestão, Educação e Tecnologia Ambiental (e-ISSN: 2236-1170)

\title{
OPORTUNIDADES DE PRODUÇÃO MAIS LIMPA NO CONSUMO DE RECURSOS HÍDRICOS NA EXPLORAÇÃO \& PRODUÇÃO DE PETRÓLEO ON SHORE NO ESTADO DO RN
}

\author{
B. R. B. Correia ${ }^{1}$; C. E. M. Jerônimo² \\ ${ }^{1}$ Especialização em Engenharia de Petroleo e Gas., Departamento de Engenharia de Petróleo e Gás Natural, \\ Universidade Potiguar, CEP 59000-000, Natal-RN, Brasil: balbinacorreia@hotmail.com \\ 2 Petroleo Brasileiro AS: $\underline{\text { c_enrique@hotmail.com }}$
}

\section{RESUMO}

Neste trabalho foi desenvolvido o levantamento de oportunidades de produção mais limpa aplicada aos recursos hídricos utilizados nos processos de exploração e produção de petróleo on shore. O estudo consistiu no levantamento bibliográfico e incursões investigativas na região produtora do estado do Rio Grande do Norte. Foram levantadas oportunidades na seguinte ordem de priorização: eliminação na fonte, minimização do consumo; reciclagem ou reaproveitamento interno ou externo, tratamento e disposição final. Os resultados apontam para projetos associados a redução de vazamentos em sistemas de bombeio de água captada para formulação de fluidos; redução dos vazamentos de vapor; utilização de água salobra/salina proveniente de poços de captação mais profundos em substituição à água doce de poços de captação; utilização/Reuso (externo) de água de esgotos em substituição à água doce captada e usada para injeção; uso de água oceânica (captada do mar) em substituição à água doce captada , para fins de recuperação secundária; adoção de equipamento/sistema de elevação de petróleo com recursos de DOWS Downhole Oil Water Separation (Separação óleo/água no fundo do poço) e uma maior automação, com a utilização de sistema de "Poços e Campos inteligentes".

Palavras-chave: Produção mais limpa, exploração, produção e petróleo.

ABSTRACT. This work presents a survey of opportunities for cleaner production applied to water used in the processes of exploration and production of oil on shore. The study consisted of literature review and investigative forays in the region of the state of Rio Grande do Norte. Opportunities arose in the following order of priority: eliminating at source, minimizing the consumption, recycling or reuse internal or external, treatment and final disposal. The results point to projects associated with the reduction of leaks in water pumping systems for the formulation of captured fluids, reduction of leakage of steam, use of brackish / saline uptake from deeper wells to replace the fresh water wells to capture; use / reuse (external) water drains, replacing the freshwater abstracted and used for injection, use of ocean water (captured from the sea) in replacement of freshwater abstracted for the purpose of secondary recovery; adoption of equipment / system increase in oil resources DOWS - Downhole Oil Water Separation and greater automation system with the use of "smart wells and fields."

Keywords: Cleaner production, exploration, production and oil. 
Rev. Elet. em Gestão, Educação e Tecnologia Ambiental (e-ISSN: 2236-1170)

\section{INTRODUÇÃO}

A água, um dos principais recursos naturais, é indispensável à vida e um elemento fundamental em vários processos produtivos. O que, portanto, o uso eficiente desse recurso é necessário para a garantia do mesmo às gerações futuras, como discorre a concepção de sustentabilidade, bem como, para o desenvolvimento e economia de uma nação.

A indústria do petróleo, para exploração de recursos naturais (óleo e gás natural), se utiliza da água na realização das suas atividades e gera efluente cujo principal resíduo da extração de petróleo é a própria água (SILVA, 2000).

A água produzida é o maior volume de subprodutos, ou fluxo de resíduos, associados à exploração e produção de petróleo e gás. Aproximadamente 21 bilhões de barris (barris; 1 bbl = 42 galões norte-americanos) de água produzida são gerados a cada ano nos Estados Unidos de quase um milhão de poços. Isso representa cerca de 57 milhões de barris/dia, 2,4 bilhões de litros/dia, ou $913.000 \mathrm{~m}^{3} /$ dia. Mais de 50 bilhões de barris de água produzida são gerados a cada ano em milhares de poços em outros países (CLARK \& VEIL, 2009).

Clark \& Veil (2009) ressaltam que o custo de administrar um volume de água tão alto é um fator chave para produtores de petróleo e gás.

Segundo Thomas (2004), a quantidade de água produzida associada com o óleo pode alcançar entre $50 \%$ e $100 \%$ (em volume) ao fim da vida econômica dos poços. Em média, para cada $\mathrm{m}^{3} /$ dia de petróleo produzido são gerados três a quatro $\mathrm{m}^{3} /$ dia de água. Há campos em que este número se eleva a sete ou mais. Nas atividades de exploração, perfuração e produção a água produzida responde por $98 \%$ de todos os efluentes gerados.

A água produzida com o óleo é um efluente cujo descarte tem de ser feito com os devidos cuidados para não agredir o meio ambiente.

Há regulamentação específica para a extração de água subterrânea na produção do petróleo e do gás natural, a qual caracteriza a água de injeção e água produzida. A Resolução CONAMA 393, no Art. 2ำ I, de 2007, impõe tratamento de efluentes na extração de petróleo e gás natural em plataformas marítimas. (GUIMARAES \& XAVIER, 2008).

Neste contexto, é primordial o gerenciamento deste recurso nos campos de exploração de petróleo, no sentido do melhor controle do uso e redução ao desperdício de água nos processos de E\&P.

A Produção mais Limpa $(\mathrm{P}+\mathrm{L})$ surge como uma alternativa a ser utilizada pelo caráter de prevenção à poluição. $O$ Centro Nacional de Tecnologias Limpas (CNTL) define $P+L$ como uma estratégia para aumentar a eficiência no uso de matérias-primas, água e energia, através da não geração, minimização ou reciclagem de resíduos e emissões geradas (CNTL, 2003).

Entre os estudos que abordam a aplicação de $\mathrm{P}+\mathrm{L}$ na indústria de petróleo, pode-se citar trabalhos realizados por Prestrelo (2006), Jerônimo et al (2007) e Campos et al (200?), que englobam a aplicação dos conceitos de $\mathrm{P}+\mathrm{L}$ no gerenciamento do uso da água em atividades de E\&P e refino de petróleo e gás. Prestelo (2006) apresenta a aplicação de $\mathrm{P}+\mathrm{L}$ em campos da Petrobras no estado da Bahia. O estudo de Campos et al (200?) utiliza a metodologia da P+L à água produzida no campo de Carmópolis, no estado de Sergipe. E Jerônimo et al (2007) discorre sobre práticas de minimização na fonte em atividades do refino de petróleo. Todos os estudos citados apontam a $\mathrm{P}+\mathrm{L}$ como uma técnica adequada e com resultados favoráveis para redução na fonte dos principais impactos associados ao consumo e poluição dos recursos hídricos. 
Rev. Elet. em Gestão, Educação e Tecnologia Ambiental (e-ISSN: 2236-1170)

A partir deste contexto, o estudo em tela busca levantar técnicas e ações de $\mathrm{P}+\mathrm{L}$ apropriados à aplicação às atividades que utilizam água para exploração de petróleo no estado do Rio Grande do Norte e Ceará. Bem como, o desenvolvimento de alternativas para o tratamento da água produzida, com intuito de prevenção e maior eficiência na utilização deste recurso, e, posteriormente, apresentar as principais oportunidades de melhorias identificadas.

\section{MATERIAIS E MÉTODOS}

O estudo constitui-se de uma pesquisa aplicada, pois objetiva levar conhecimentos para extensão das tecnologias de $\mathrm{P}+\mathrm{L}$ levantadas e avaliadas em estudo de viabilidade técnica e econômica.

Do ponto de vista dos objetivos, trata-se de um estudo exploratório-descritivo, o qual visa descrever a problemática em discussão, buscando caracterizar o objeto de estudo.

A hipótese pauta-se na possibilidade de haver viabilidade técnica e econômica para modificar determinadas atividades de E\&P de petróleo e gás natural com uso de tecnologias limpas no que concerne à utilização de recursos hídricos, para atingir um uso racional e eficiente deste recurso.

Do ponto de vista dos procedimentos técnicos, o estudo caracteriza-se como pesquisa bibliográfica, por sua elaboração partir do levantamento e análise de material já publicado, como artigos científicos, livros, relatórios técnicos, etc. e (GIL apud SILVA \& MENEZES, 2001), e como estudo de caso devido à utilização de dados de campo.

A estrutura da pesquisa consiste em:

- Formulação do problema, englobando a justificativa do estudo, a determinação dos objetivos, a contextualização da problemática e definição da metodologia;

- Realização do levantamento teórico, que orienta a caracterização do objeto de estudo, as definições e conceitos a serem utilizados em análise e correntes de pensamentos que norteiam a hipótese da pesquisa;

- Levantamento de dados em campo, por meio de incursões investigativas em campos de petróleo no estado do Rio Grande do Norte e Ceará, tais como: Canto do Amaro, Riacho da Forquilha e Fazenda Belém;

- Estudo criterioso sobre os princípios de $P+L$ e as ações a serem aplicadas na prática das atividades apresentadas, que tenham viabilidade técnica;

- Realizar uma análise econômica das oportunidades de aplicação identificadas e discussão sobre as melhorias que possam acarretar.

Os dados coletados em campos foram organizados, de acordo com a necessidade da utilização em pesquisa, e utilizados para elaboração do levantamento das principais ações de oportunidades. 
Rev. Elet. em Gestão, Educação e Tecnologia Ambiental (e-ISSN: 2236-1170)

\section{A PRODUÇÃO MAIS LIMPA E A UTILIZAÇÃO DA ÁGUA}

\subsection{0 uso da água}

No Brasil, "o Conselho Nacional do Meio Ambiente (CONAMA) é órgão consultivo e deliberativo do Sistema Nacional do Meio Ambiente (SISNAMA), foi instituído pela Lei 6.938/81, que dispõe sobre a Política Nacional do Meio Ambiente, regulamentada pelo Decreto 99.274/90" (CONAMA apud NOVATO \& COSTA et. al, 2006).

A Lei 9.433, de 08/01/97, chamada Lei das Águas, estabelece a Política Nacional de Recursos Hídricos (PNRH), cujo objetivo principal é assegurar a disponibilidade de água à atual e às futuras gerações, com qualidade adequada ao uso, buscando a prevenção e desenvolvimento sustentável, com a utilização racional e integrada desse recurso (BRAGA \& FLECHA, 2008).

Entre as diretrizes gerais de ação que orientam a PNRH, segundo Braga \& Flecha (2008), estão: articulação dos recursos hídricos com a gestão ambiental; articulação do planejamento dos recursos hídricos com o dos setores usuários e com os planejamentos regionais, estaduais e nacionais; articulação dos recursos hídricos com a gestão do uso do solo; e gestão sistemática dos recursos hídricos sem dissociação dos aspectos de quantidade e qualidade.

A Agência Nacional de Águas (ANA), "uma autarquia sob regime especial, com autonomia administrativa e financeira, vinculada ao Ministério do Meio Ambiente, conduzida por uma Diretoria Colegiada", criada pela Lei 9.984/2000, tem a função de reguladora do uso da água bruta nos corpos hídricos do domínio da União (Lei 12.058/2009, regulação de serviços de adução de água bruta) e coordenar a implementação da Política Nacional de Recursos Hídricos (BRASIL, 2012).

A Figura 1 apresenta o resultado das estimativas da demanda de água para uso consuntivo por setores, em pesquisa realizada pela ANA em 2010.
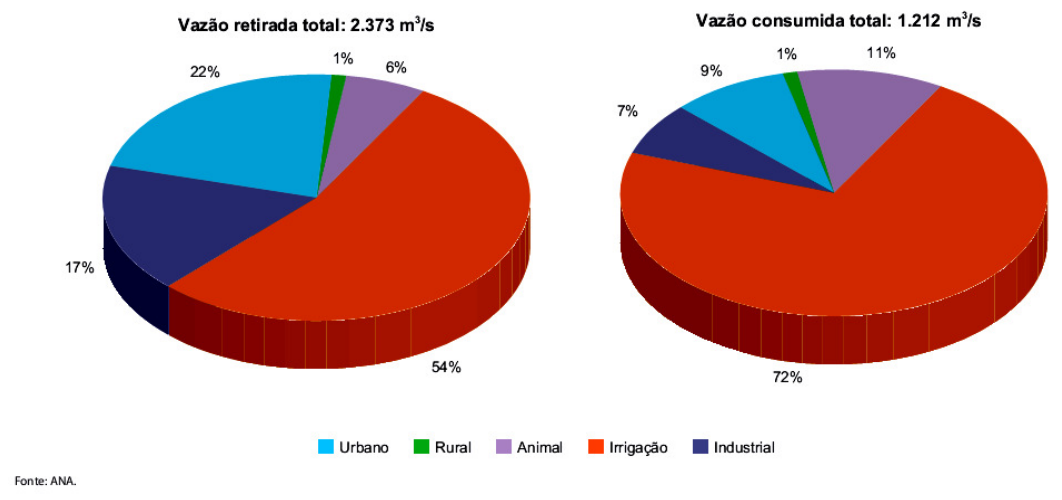

Figura 1. Demandas consuntivas de água no Brasil. Fonte: ANA (2012).

Das vazões retiradas $54 \%$ foram para irrigação e $17 \%$ do setor industrial. Já em relação à vazão total consumida, $72 \%$ foram para irrigação e $7 \%$ para abastecimento industrial.

De acordo com dados da ANA (2009), cerca de 18\% da água total captada para usos consuntivos, no Brasil, são utilizados para indústrias e agroindústrias e uma geração de efluentes da ordem de $86 \%$. Contudo, o uso eficiente é pouco observado. A redução do consumo de água 
Rev. Elet. em Gestão, Educação e Tecnologia Ambiental (e-ISSN: 2236-1170)

em indústria têxtil em São Paulo chegou a 30\%, e no setor petroquímico brasileiro a racionalização do uso de água variou de $15 \%$ a $25 \%$.

No que concerne a práticas de uso racional de água pelo setor industrial, a ANA (2009) cita a indústria sucro-alcooleira que tem adotado práticas com redução substancial dos níveis de captação e lançamento, que em 1997 eram captados cerca de $5 \mathrm{~m}^{3}$ de água para processamento de 1 tonelada de cana e em 2004 passou para $1,8 \mathrm{~m}^{3}$ de água para a mesma atividade.

\subsection{Produção Mais Limpa}

O conceito da Produção Mais Limpa foi designado pela United Nations Environmental Program - UNEP, em 1988, como a aplicação contínua de uma estratégia preventiva e integrada, aplicada a processos, produtos e serviços (OLIVEIRA \& ALVES, 2007).

A UNIDO (United Nations Industrial Development Organization) define a $\mathrm{P}+\mathrm{L}$ como:

"[...] a aplicação de uma estratégia técnica, econômica, ambiental e tecnológica integrada aos processos e produtos, a fim de aumentar a eficiência no uso de matérias-primas, água e energia, através da não geração, minimização ou reciclagem dos resíduos gerados, com benefícios ambientais e econômicos para os processos produtivos" (FIESP apud ESPINOSA \& BACHEGA, 2011).

$A P+L$ é, desta forma, o conjunto de ações destinadas à prevenção da geração de resíduos e efluentes, ou, em sua última instância, a reutilização de rejeitos dos processos produtivos, que podem ser aplicadas nas várias etapas dos processos de transformação, partindo do planejamento de produtos e processos até a destinação adequada e retorno de resíduos.

A Figura 2 mostra, em detalhes, os níveis de atuação da $\mathrm{P}+\mathrm{L}$, em prioridades.

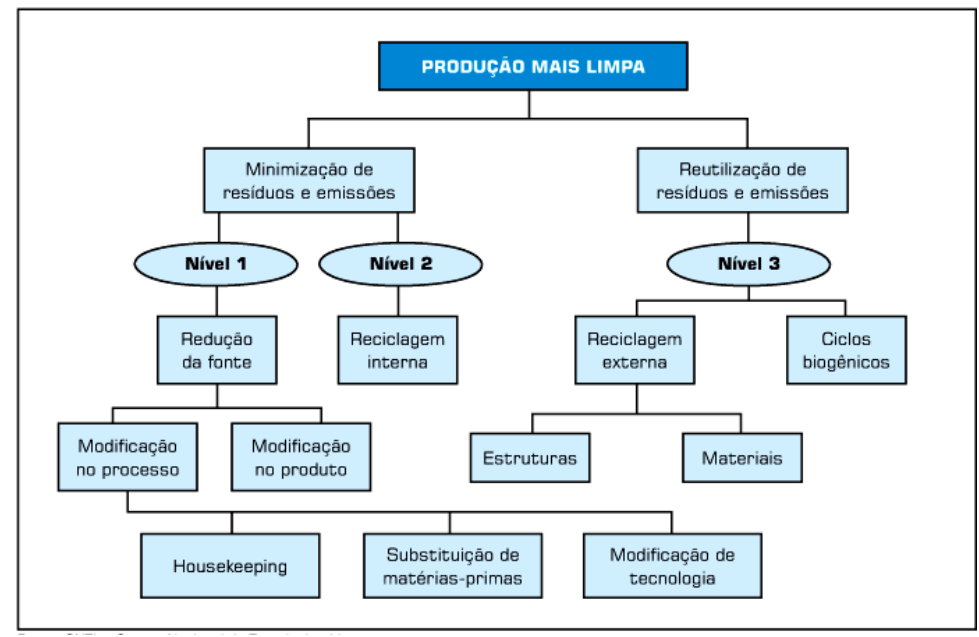

Figura 2. Escopo de atuação da metodologia $\mathrm{P}+\mathrm{L}$.

Fonte: CNTL apud OLIVEIRA \& ALVES (2007).

Técnicas de $\mathrm{P}+\mathrm{L}$ incluem conservação de energia e matérias-primas, eliminação de material tóxico nos processos e a redução da quantidade e toxicidade de todas as emissões e resíduos, cuja estratégia do programa $\mathrm{P}+\mathrm{L}$ "enfoca a redução dos impactos ambientais ao longo de todo ciclo de 
Rev. Elet. em Gestão, Educação e Tecnologia Ambiental (e-ISSN: 2236-1170)

vida do produto". A P+L pode ser obtida pela "aplicação de perícia, de melhoria tecnológica e mudancas de atitude" (BAAS apud MEDEIROS \& CALÁBRIA et. al, 2007).

Berkel (2000) cita cinco práticas de prevenção mais comum nas indústrias:

1. Modificacões no produto: alterações na composição, tipo de embalagem e tempo de vida útil dos produtos:

2. Substituicão de matéria-prima: utilizar matéria-prima e insumos menos poluentes e com maior vida útil:

3. Mudancas na tecnologia: melhoria na automacão de nrocessos, otimização de processos. redesenho eauibamento e substituicão processo:

4. Housekeebina: mudancas nos procedimentos operacionais e na gestão. para eliminar resíduos e emissões. como prevencão a derramamento e treinamentos de funcionários:

5. Reciclagem no local: ou seia. reciclagem interna, aplicações de resíduos e poluentes nos processos onde foram gerados.

\section{RESULTADOS E DISCUSSÕES}

\subsection{Os recursos hídricos na E\&P de petróleo e gás natural}

A água é amplamente utilizada nos processos de exploração e produção de petróleo (E\&P), seja na recuperação secundária, na utilização de equipamentos ou na adição aos fluidos de perfuração e completação, com uso de água doce ou geração de água produzida (GALVÃO \& XAVIER, 200?).

Prestrelo (2006) cita as principais utilizações de água doce nas atividades desenvolvidas no Brasil, a saber:

a) Recuperação secundária convencional de petróleo (injeção de água para repressurização de reservatórios de petróleo);

b) Recuperação secundária por métodos especiais (injeção de vapor);

c) Outros processos de uso industrial em plantas e instalações, incluindo refrigeração/troca de calor;

d) Uso doméstico para sanitários e jardinagem;

e) Cessão a comunidades próximas ao entorno de suas operações;

f) Preparação de fluidos de perfuração e completação em sondas de Perfuração e de Produção.

Por esta razão, compete a E\&P a racionalização e o uso eficiente da água sob uma perspectiva de prevenção a poluição e ao desperdício.

É interessante comentar sobre a poluição que os fluidos de perfuração podem trazer ao meio ambiente. Comumente conhecido como lamas de perfuração, Mariano (2007) explica que:

“O perigo para o meio ambiente das lamas de perfuração está relacionado, particularmente, à presença de materiais lubrificantes na sua composição. [...] Os lubrificantes são adicionados nos fluidos de perfuração desde o início, como parte das formulações originais ou no decorrer do processo, quando as necessidades operacionais aparecem. Em ambos os casos, as lamas utilizadas e os cascalhos cobertos por esses fluidos contêm consideráveis quantidades de hidrocarbonetos estáveis e tóxicos, assim como de um grande espectro de muitas outras substâncias". 
Rev. Elet. em Gestão, Educação e Tecnologia Ambiental (e-ISSN: 2236-1170)

Das utilizações de recursos hídricos na exploração e produção de petróleo e gás identificados em literatura, a injeção de água (recuperação suplementar) e a água produzida (associada ao petróleo), mostraram-se mais abordadas no estado da arte. Por esta razão, o estudo foca esses aspectos em detrimento dos demais, sem intento de levar o tema à exaustão.

A recuperação secundária é utilizada quando ocorre a redução na produtividade do poço, devido ao decréscimo na pressão e temperatura do reservatório, durante sua vida produtiva. $A$ dissipação da energia primária dos reservatórios leva a necessidade de suplementá-la com energia secundária, artificialmente, por meio da injeção de fluidos em poços selecionados (ROSA et al, 2006).

Esta técnica objetiva manter ou aumentar a pressão do reservatório e, consequentemente, aumentar a eficiência de recuperação e acelerar a produção em relação à produção primária. Há dois tipos de recuperação secundária: injeção de água e injeção de gás. A água a ser injetada pode ser a água captada ou produzida com o óleo, esta pode ser injetada no próprio óleo ou no aquífero. Ambas devem ser tratadas (SANTOS et al, 2010).

A água injetada no reservatório de petróleo atua expulsando o óleo do reservatório para que este seja deslocado ao poço, ou no próprio aquífero para manter a pressão, caso este não seja atuante.

A Figura 3 mostra a injeção de água no reservatório de petróleo e no aquífero, respectivamente.

A água de injeção, normalmente, vem da superfície, de rios, lagos, represas, oceanos, e de aquíferos por meio de captação de poços, ou do próprio poço produtor que produz óleo e água (Santos et al, 2010).
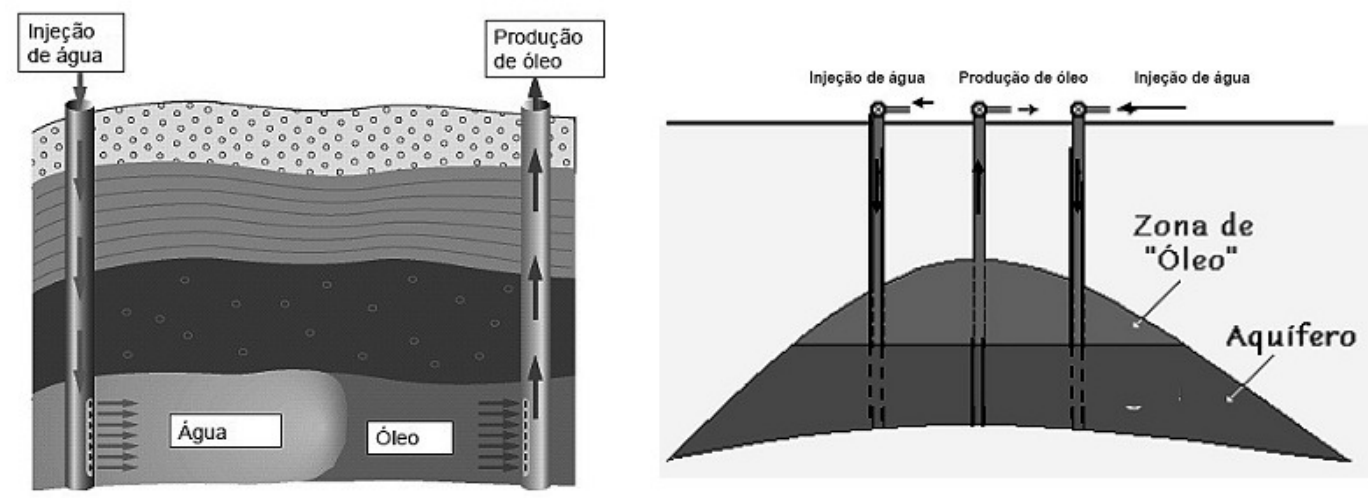

Figura 3. Injeção de água, no reservatório e no aquífero.

Fonte: Santana apud Santos et al (2010).

Nos Estados Unidos a maior parte da água produzida, gerada em poços onshore, é injetada em reservatório para manter a pressão no reservatório e acelerar a produção de óleo. No ano de 1995, 71\% da água produzida gerada nos EUA já era utilizada para recuperação secundária, o que torna a água um recurso de produção ao invés de um resíduo da produção (CLARK \& VEIL, 2009).

Ribeiro apud Prestrelo (2006) descreve que a fonte ideal de água para injeção apresenta certas características, entre elas: suficiente disponibilidade de água em qualquer época; fácil acesso de adução; acesso fácil entre fonte e local de uso; baixo teor de sólidos suspensos; ser 
Rev. Elet. em Gestão, Educação e Tecnologia Ambiental (e-ISSN: 2236-1170)

compatível com o sistema rocha-fluidos; isenta de bactérias ou outros microrganismos; ser não corrosiva; e não conter sulfatos e bicarbonatos.

Em resumo, a água a ser injetada deve ser compatível com as características da água da formação, seja água doce ou água do mar a ser injetada. O que, portanto, requer um tratamento da água anterior a injeção.

Prestrelo (2006) explicita que a injeção de água respondia por $50 \%$ do consumo de água doce em campos da Bahia, em 2006. A Figura 4 mostra a produção de óleo e o volume de água doce injetada na referida região.

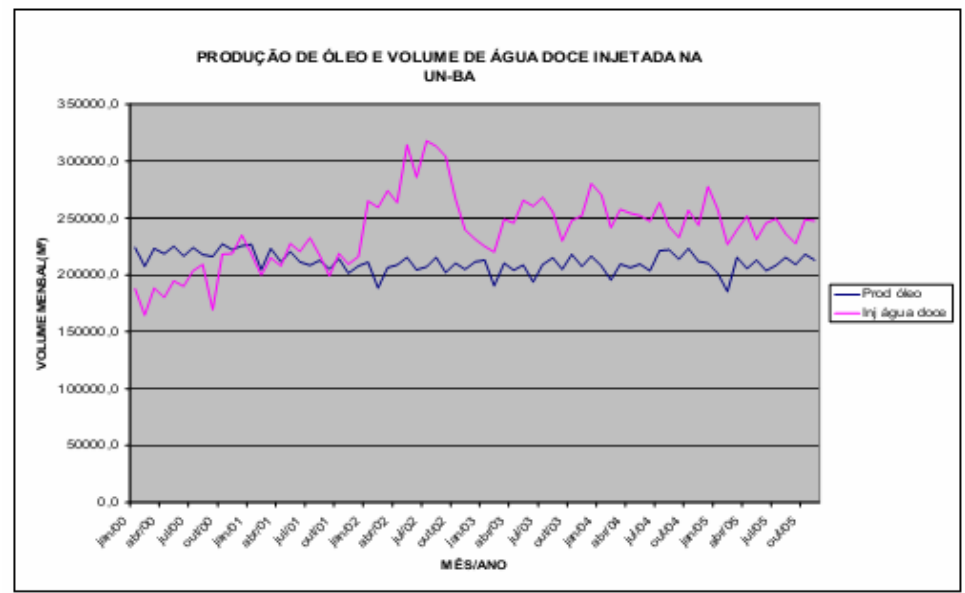

Figura 4. Produção de óleo e volume de água doce injetado.

Fonte: Prestrelo (2006)

Prestrelo (2006) ressalta, ainda, que ao longo de janeiro de 2000 a outubro de 2005, o volume de água doce injetado, em três campos da Bahia, foi cerca de $20 \%$ maior do que o volume de óleo produzido.

Há dois índices associados à geração de água produzida, o BSW - Basic Sediments and Water e o RAO - Razão água/óleo, os quais aumentam com o amadurecimento dos campos de petróleo, acarretando aumentos nos custos da extração, tratamento/separação, e re-injeção de água. Devido à contínua injeção de água, os valores de BSW e RAO aumentam o que indica o aumento da geração de água produzida (PRESTRELO, 2006).

No que diz respeito à água produzida, esta possui características específicas, visto que é o resíduo associado ao óleo extraído do reservatório. A chamada água produzida (AP) constitui um dos principais problemas associados à atividade de extração de petróleo, a qual é o efluente que resulta dos processos de separação nas estações coletoras e de tratamentos dos campos de produção de petróleo. Portanto, é pertinente o correto manejo e disposição da água produzida, que compõe a maior parte do volume gerado na E\&P de petróleo e gás, sendo levada à superfície em emulsão, junto com óleo e gás (CAMPOS et al, 200?).

A AP pode ser a existente no reservatório de óleo desde a sua formação, chamada água conata, ou a sua mistura com a água subterrânea que pode estar sendo utilizada em processos de recuperação secundária denominada de água de injeção (SILVA, 2000).

De acordo com Clark \& Veil (2009), nos Estados Unidos a água produzida representa o maior volume de resíduo gerado pela indústria de petróleo e gás, compreendendo 
Rev. Elet. em Gestão, Educação e Tecnologia Ambiental (e-ISSN: 2236-1170)

aproximadamente $98 \%$ do volume total de resíduos da E\&P. Os autores mencionam estimativas de Khatib \& Verbeek, onde ressaltam que, em 1999, uma média de 210 milhões de barris de água foi produzida a cada dia em todo o mundo, um volume que denota cerca de 77.000 milhões de barris de água produzida em um ano.

Segundo Silva (2000) a água produzida contém, geralmente, alta salinidade, partículas de óleo em suspensão, metais pesados, produtos químicos adicionados nos processos de produção, e mesmo radioatividade. O autor cita que o fato torna a AP um poluente de difícil descarte, agravando-se devido ao significativo volume produzido.

A água produzida é um efluente complexo, cuja composição pode variar amplamente, dependendo da idade e tipo do campo, origem e qualidade do óleo e procedimentos utilizados na extração. Os compostos que geralmente constituem esta água são: sais minerais dissolvidos; óleo disperso e dissolvido; sólidos originados da corrosão; graxas e asfaltenos; produtos químicos adicionados para prevenir e/ou tratar problemas operacionais, como - inibidores de corrosão, anti-incrustantes, anti-espumantes, biocidas e gases, como dióxido de carbono $\left(\mathrm{CO}_{2}\right)$ e gás sulfídrico $\left(\mathrm{H}_{2} \mathrm{~S}\right)$ (STEPHENSON apud ANDRADE, SOLETTI \& CARVALHO, 2009).

No processo de exploração de petróleo em Sergipe, são gerados aproximadamente 40.000 $\mathrm{m}^{3} / \mathrm{d}$ de água oleosa, denominada de água produzida, a qual contém em torno de $1000 \mathrm{mg} / \mathrm{L} \mathrm{de}$ óleos e graxas (TOG) e $200 \mathrm{mg} / \mathrm{L}$ de sólidos suspensos. Essas quantidades de água tendem a aumentar ao longo da vida produtiva do campo petrolífero, chegando a quase $100 \%$ no final da vida do poço segundo dados da Petrobras, em 2009 (apud GOMES, 2009).

Conforme explica Silva (2000), a água produzida deve passar por tratamentos eficazes para se enquadrar na legislação vigente, dependendo do destino a ser dado. Se for reutilizada, precisa ser tratada de modo a atingir os padrões necessários ao processo em que será utilizada.

A Resolução CONAMA № 430/2011 dispõe sobre as condições para lançamento de efluentes, de qualquer fonte poluidora, diretamente no corpo receptor: $\mathrm{pH}$ entre 5 a 9; e temperatura, inferior a $40{ }^{\circ} \mathrm{C}$ (variação de temperatura do corpo receptor não deverá exceder a 3ㅇ C no limite da zona de mistura). E delibera sobre a presença de óleo na água a ser disposta no mar, até 20 mg/L (BRASIL, 2011). "Na água a ser injetada, a presença de óleo pode levar à queda de injetividade, especialmente se a injeção estiver se realizando em uma zona que não tenha contido óleo anteriormente (poço de descarte)" (SILVA, 2000).

Ainda de acordo com Silva (2000), os tratamentos básicos na qual a água produzida pode passar são: remoção de óleo residual; remoção de gases; remoção de sólidos suspensos; eliminação de bactérias. As opções potenciais para a disposição ou reciclagem da Água Produzida são basicamente: disposição no solo; disposição em rios; irrigação; água potável; descarte no mar; descarte no subsolo; e água de injeção.

Como exemplo de quantidade de água produzida nos campos de petróleo pode-se utilizar dados de Prestrelo (2006), na Figura 5, que mostra a evolução do descarte volumétrico de água produzido em três campos da Bahia, de janeiro de 2000 a outubro de 2005 . O autor elucida que se comparado o volume que é descartado de água produzida e a água doce que é injetada, constatase que o volume descartado é bem inferior ao volume de água doce utilizado para recuperação secundária (injeção de água). 
Rev. Elet. em Gestão, Educação e Tecnologia Ambiental (e-ISSN: 2236-1170)

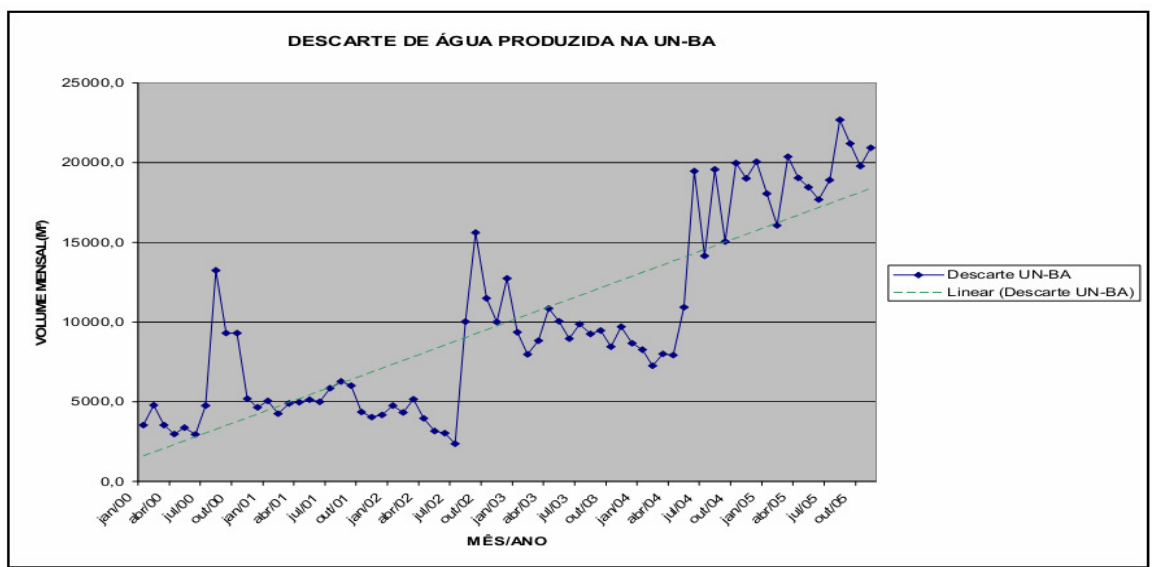

Figura 5. Descarte volumétrico de água produzida.

Fonte: Prestrelo (2006).

Não obstante, tanto a injeção de água doce e o descarte de água produzida são aspectos significativos do ponto de vista ambiental. Prestrelo (2006) discute a questão ambiental do uso da água doce, e cita autores que argumentam a indisponibilidade do uso de água doce para fins de injeção, interferência no ciclo hidrológico e a prioridade do uso de água doce para consumo humano como motivos para sua não utilização em recuperação secundária.

Os autores debatidos por Prestrelo (2006) elucidam que em outra perspectiva, os custos de utilização de água do mar na injeção, dependem da composição da água e características do reservatório, pode ser de custos elevado, com tratamento antes da injeção.

Ademais, a água produzida pode causar efeitos nocivos ao meio ambiente devido a sua composição e quantidade, devendo ser tratada para ser descartada. Tanto por aspectos ambientais quanto econômico é primordial o controle sobre a água de injeção e água produzida.

Silva (2000) evidencia que "o controle desta produção [água produzida] é de grande interesse para produtores de petróleo", pois o custo na extração de petróleo inclui a produção de água, a separação óleo/água, a disposição da água produzida, geralmente salgada, que impossibilita o descarte em operações onshore. "A diminuição da produção de água pode levar a otimização do custo com a produção de petróleo, refletindo nos processos de separação e tratamento do óleo". Sem abordar as melhorias ambientais com a redução de água produzida (SILVA, 2000).

\subsection{Levantamento de oportunidades em $P+L$ em processos de E\&P de petróleo e gás}

Da pesquisa bibliográfica realizada foram identificadas algumas ações de prevenção condizentes com a filosofia da $P+L$ para operações de E\&P da indústria de petróleo e gás natural que utilizam recursos hídricos. Entre os autores que abordam as ações de $P+L$ estão Prestrelo (2006) e Jerônimo et al (2007), principalmente.

Jerônimo et al (2007) elenca as oportunidades de redução/eliminação do uso de recursos hídricos nos processo de refino de petróleo e classifica essas oportunidades de acordo com área de abrangência. Entre as oportunidades citadas pelos autores, àquelas se enquadram nas atividades das etapas de exploração e produção, são: 
Rev. Elet. em Gestão, Educação e Tecnologia Ambiental (e-ISSN: 2236-1170)

1. Vazamento de vapor: redução e/ou eliminação do consumo;

2. Vazamentos em válvulas (para E\&P Vazamentos em sistemas de bombeio de água captada para formulação de fluidos): redução e/ou eliminação do consumo;

3. Consumo desnecessário de vapor no processo: Alteração de processo;

4. Controle do consumo excessivo de água: alteração na forma de tratamento;

Prestrelo (2006) seleciona as alternativas potenciais de aplicação a partir da sequência prioritária definida pelo organograma mestre de prevenção da poluição de La Grega:

- Reduzir na fonte;

- Reutilizar/reciclar internamente

- Reutilizar/reciclar externamente

- Tratamento/regeneração

- Disposição final.

A redução na fonte depende de mudanças no produto e controle na fonte. Quanto ao primeiro aspecto mostra-se inviável tecnicamente, já que o produto é o fluido produzido (petróleo e/ou gás), e o segundo aspecto refere-se à minimização da geração de resíduos líquidos, a água produzida, e minimização do consumo de água doce utilizada para complementar a AP para recuperação secundária. As alternativas apresentadas por Prestrelo (2006) são:

- Mudança de Insumo:

1. Utilização de água salobra/salina proveniente de captação mais profundo em substituição à água doce de poços de captação;

2. Utilização/reuso (externo) de água de esgotos em substituição à água doce captada e usada para injeção;

3. Uso de água oceânica em substituição à água doce para fins de recuperação secundária;

- Mudanças de tecnologia

1. Adoção de poços perfurados e completados horizontamente (quando possível) para melhor controle de AP;

2. Adoção de equipamento/sistema de elevação de petróleo com recursos de DOSW Downhole Oil Water Separation (Separação óleo/água no fundo do poço);

3. Maior automação, com a utilização de sistema de "Poços e Campos inteligentes";

4. Emprego de tecnologia de aplicação de polímeros para redução da geração de AP;

5. Aplicação da tecnologia de bioestimulação de reservatórios;

6. Aplicação da Tecnologia de Dump-Flooding para injeção de água;

- Reciclagem interna e externa

1. Regeneração e reuso: maximizar a regeneração e o reuso de toda a corrente de água produzida proveniente o processo de produção como água de injeção para a recuperação secundária;

2. Recuperação: processamento para regeneração da água produzida para possibilitar a reutilização da mesma como água potável ou como água de irrigação de plantações;

- Disposição final de resíduos

1. Disposição da água produzida em poços de descarte;

2. Descarte de água produzida em Lagoas/Bacias de Evaporação; 
Rev. Elet. em Gestão, Educação e Tecnologia Ambiental (e-ISSN: 2236-1170)

3. Descarte de água produzida para corpos d'água (rios ou lagos).

No estudo realizado em campos produtores, localizados no centro da Bacia do Recôncavo Bahiano e explorados pela Petrobras, Silva (2000) discorre sobre a água produzida (AP) nos campos e faz análise de amostras na perspectiva de gerenciamento da AP durante a extração do petróleo, sob possibilidades de minimização de sua produção.

O autor elucida a importância em evitar o descarte inadequado de efluentes, pois estes são passíveis de causar efeitos nocivos ao meio ambiente, penalidades diversas e custos elevados com medidas corretivas e mitigadoras, além de repercussão negativa.

De acordo com Silva (2000), no que se refere a AP as seguintes ações podem ser tomadas:

1. Controles tradicionais na produção de água: controlar a produção de água e recuperar o potencial produtor do poço;

2. A água produzida pode ser descartada adequadamente: tratamentos básicos de acordo com a legislação vigente, como remoção de óleo residual, de gases, de sólidos suspenso e eliminação de bactérias;

3. Utilização da AP nos processos de injeção para recuperação secundária: realizado um tratamento preliminar da água para compatibilidade com água da formação;

4. Melhoria na qualidade injetada: adequação a zona de injeção, uso de polímeros e tratamento de zonas produtoras pode contribuir para a diminuição no volume da água produzida e em maior produção de óleo;

5. Utilização para irrigação: após tratamento adequado, a AP para irrigação pode suplementar as reservas de águas de regiões de baixo índice pluviométrico;

Segundo Allen \& Robinson apud Silva (2000), na Califórnia a AP é utilizada para atividades de irrigação, "onde a média de chuvas se situa entre 100 e 200 mm por ano".

Silva (2000) cita o isolamento da zona produtora de óleo e portadora de alta saturação de água (alto BSW) como controle tradicional executado. $O$ isolamento pode ser realizado por: obturadores mecânicos, quando a zona a isolar localizar abaixo de outras existentes; ou compressão de cimentos (squeeze), quando a zona a isolar se localizar acima de outra zona produtora a ser preservada.

Considerando as informações coletadas em estudo e as observações em campo de poços de petróleo no Rio Grande do Norte e Ceará, em campos do Canto do Amaro, Riacho da Forquilha e Fazenda Belém, foram separadas as seguintes oportunidades de ações de $P+L$ com potencial de aplicação na referida região:

- Eliminação ou redução dos vazamentos em sistemas de bombeio de água captada para formulação de fluidos;

- Eliminação ou redução dos vazamentos de vapor;

- Utilização de água salobra/salina proveniente de poços de captação mais profundos em substituição à água doce de poços de captação;

- Utilização/Reuso (externo) de água de esgotos em substituição à água doce captada e usada para injeção; 
Rev. Elet. em Gestão, Educação e Tecnologia Ambiental (e-ISSN: 2236-1170)

- Uso de água oceânica (captada do mar) em substituição à água doce captada , para fins de recuperação secundária;

- Adoção de equipamento/sistema de elevação de petróleo com recursos de DOWSDownhole Oil Water Separation (Separação óleo/água no fundo do poço);

- Maior automação, com a utilização de sistema de "Poços e Campos inteligentes".

Essas alternativas são compatíveis com as necessidades e facilidades técnicas disponíveis na região estudada e favorecem a mitigação de impactos ao meio ambiente, de forma aderente aos conceitos da produção mais limpa.

\section{CONCLUSÃO}

Com base nas pesquisas bibliográficas e resultados obtidos é possível concluir que:

1. A metodologia da produção mais limpa é aplicável ao desenvolvimento de oportunidades de melhorias no desempenho ambiental das atividades de exploração e produção on shore.

2. A utilização de recursos hídricos no processo de exploração e produção é muito freqüente e presente em grandes volumes, sendo um impacto ambiental significativo e que deve ter sua apropriação no gerenciamento ambiental das organizações que atuam nesse segmento.

3. As oportunidades identificadas na exploração no estado do Rio Grande do Norte apontam para as melhorias mais significativas com a eliminação ou redução de vazamentos de água e vapor e utilização de alternativas de recursos hídricos de maior disponibilidade e/ou qualidade inferior.

4. Foram identificadas oportunidades que impõe a necessidade de elevados níveis de investimentos financeiros, porém, que tendem a gerar resultados econômicos significativos. Logo, sugere-se que estudos complementares sejam realizados para mensurar os ganhos econômicos das oportunidades identificadas.

\section{REFERENCIAS BIBLIOGRÁFICAS}

1. ANA, AGÊNCIA NACIONAL DE ÁGUAS, CEBDS. Água: Fatos e tendências. 2o ed. ANA; CEBDS, Brasília, 2009. Disponível em<20100312110010_Revista_Fatos_e_Tendencias_2009.pdf>. Acesso em 12 de maio/2012.

2. BENKEL, R.V. Cleaner production for process industries: Overview of the cleaner production concept and relation with other environmental management strategies. Curtin University of Technology. Plenary Lecture - CHEMECA 2000, Perth WA, 9-12, Australia, 2000. Disponível em < http://infohouse.p2ric.org/ref/13/12031.pdf>. Acesso em 12 de maio/2012.

3. BRAGA, P.F.B.; FLECHA, R.; PENA, D.S.; KELMAN, J. Pacto federativo e gestão de águas. Scielo: Estud. Av. vol. 22, no 63, São Paulo, 2008. Disponível em <http://dx.doi.org/10. 1590/S0103-40142008000200003>. Acesso em 12 de maio/2012.

4. BRASIL, MINISTÉRIO DO MEIO AMBIENTE. Agência Nacional de Águas - ANA. Disponível em < http://www2.ana.gov.br/Paginas/institucional/SobreaAna/Default.aspx>. Acesso em 12 de maio/2012. 
Rev. Elet. em Gestão, Educação e Tecnologia Ambiental (e-ISSN: 2236-1170)

5. BRASIL, MINISTÉRIO DO MEIO AMBIENTE. Resolução № 430, de 13 de maio de 2011. Conselho Nacional do Meio Ambiente - CONAMA, 2011. Disponível em <http://www.saude.mg.gov.br/publicacoes/estatistica-e-informacaoem-saude/residuos-de-servicos-de-saude/RE\%20CONAMA\%20403-2011_Lancamento\%20de\%20Efluentes.pdf> Acesso em 16 de maio/2012.

6. BRASIL. Resolução CONAMA n 393, de 08 de Agosto de 2007. Diário Oficial da União, 2007.

7. BRASIL. Resolução CONAMA No. 357, de 17 de março de 2005. Publicada no DOU no 053, de 18/03/2005, págs. 58-63. Dispõe sobre a classificação dos corpos de água e diretrizes ambientais para o seu enquadramento, bem como estabelece as condições e padrões de lançamento de efluentes, e dá outras providências.

8. CLARK, C.E., \& J.A. VEIL. Produced Water Volumes and Management Practices in the United States, ANL/EVS/R09/1, prepared by the Environmental Science Division, Argonne National Laboratory for the U.S. Department of Energy, Office of Fossil Energy, National Energy Technology Laboratory, 2009. Disponível em < http://www.ead.anl.gov/pub/doc/ANL_EVS_R09_produced_water_volume_report_2437.pdf>Acesso em 01 de abril/2012.

9. CNTL, Centro Nacional de Tecnologias Limpas SENAI-RS/UNIDO/INEP. Implementação de Programas de Produção mais Limpa. SENAI-RS. Porto Alegre, 2003. 42 p. Disponível em < http://www.ifm.org.br/moodle/file.php/19/CNTL_guia_P_L.pdf> Acesso em 20 de março/2012.

10. ESPINOSA, J.W.M.; BACHEGA, S.J. Aplicação de conceitos de produção mais limpa em uma universidade: uma pesquisa-ação sobre reciclagem... In Anais: XXXI Encontro Nacional de Engenharia de Produção. Abepro, Belo Horizonte 2011.

11. GUIMARAES, P. B. V. \& XAVIER, Y. M. de A. Água produzida e gestão ambiental na indústria de combustíveis brasileira. In: Revista Âmbito Jurídico, Rio Grande, 57, 30/09/2008 [Internet]. Disponível em <http://www.ambito-juridico.com.br/site/index.php?n_link=revista_artigos_leitura\&artigo_id=5161>. Acesso em 02 de abril/2012.

12. JERONIMO, C. E. M. et al. Redução, reciclagem e eliminação na fonte do consumo e minimização da poluição da água no processo do refino do petróleo. In: I Simpósio de Recursos Hídricos do Norte e Centro-Oeste. Cuiabá, 2007. Disponível em: < http://www.abrh.org.br/novo/i_simp_rec_hidric_norte_centro_oeste05.pdf>.

13. MARIANO, J.B. Proposta de metodologia de avaliação integrada de riscos e impactos ambientais para estudos de avaliação ambiental estratégica do setor de petróleo e gás natural em áreas offshore. Tese de Doutorado, Universidade Federal do Rio de Janeiro - UFRJ, Rio de Janeiro, 2007.

14. MEDEIROS, D.D.; CALÁBRIA, F.A.; SILVA, G.C.S.; SILVA FILHO, J.C.G. Aplicação da produção mais limpa em uma empresa como ferramenta de melhoria contínua. Scielo: Rev. Produção, v. 17, n. 1, p. 109-128, 2007. Disponível em < http://www.scielo.br/scielo.php?script=sci_arttext\&pid=S0103-65132007000100008\&lang=pt>. Acesso em 02 de abril/2012.

15. NOVATO, A.P.S.; COSTA, C.E.S.; JERÔNIMO, C.E.M.; BRAGA, E.A. Levantamento e priorização de oportunidades de produção mais limpa para os recursos hídricos em refinarias de petróleo. Trabalho final de curso, especialização em processamento de petróleo. Instituto de Química, UERJ/Petrobras, Rio de Janeiro, 2006.

16. OLIVEIRA, J.F.G.; ALVES, S.M. Adequação ambiental dos processos de usinagem utilizando produção mais limpa como estratégia de gestão ambiental. Scielo: Rev. Produção, v. 17, n. 1, p. 129-138, 2007. Disponível em <http://www.scielo.br/scielo.php?script=sci_arttext\&pid=S0103-65132007000100009\&lang=pt>. Acesso em 02 de abril/2012.

17. SILVA, C. R. R. Água produzida na extração de petróleo. Monografia a Escola Politécnica da Universidade Federal da Bahia - $\quad$ UFBA. Disponível em <http://www.teclim.ufba.br/site/material_online/monografias/mono_remi_r_silva.pdf> Acesso em 03 de abril/2012.

18. THOMAS, José Eduardo (org.). Fundamentos de engenharia do petróleo. 2 ed. Interciência/PETROBRAS. Rio de Janeiro, 2004.

19. VEIL, J.A., M.G.; PUDER, D.; ELCOCK, \& R.J. REDWEIK, Jr.. A White Paper Describing Produced Water from Production of Crude Oil, Natural Gas, and Coal Bed Methane, prepared by Argonne National Laboratory for the U.S. Department of Energy, National Energy Technology Laboratory, 2004. Disponível em < http://www.evs.anl.gov/pub/doc/producedwaterswp0401.pdf> Acesso em 01 de abril/2012. 